dissection. In this patient we used a 2-step combined technique: first, positioning of the Djumbodis stent with traditional ascending aorta replacement to avoid surgical aortic arch correction with a relatively easy and reproducible technique; second, transfemoral artery stent grafting of the thoracic aorta to correct pseudoaneurysm and residual dissection. It appears to be a useful procedure mainly in high-risk situations, such as elderly patients with comorbidities in whom aortic arch replacement has a prohibitive surgical risk. The Djumbodis system has also facilitated distal aortic procedures because the long steel stent permits a safe proximal landing zone for deployment of thoracic aortic stent grafts. Control CT scans 2 and 5 months after the last procedure showed the perfect position of the Djumbodis and thoracic stent grafts; the aortic arch was not dilated, and the resulting pseudoaneurysm false lumen was thrombosed. At 7 months' follow-up, the patient is alive and asymptomatic. This combined surgical and endovascular approach might be a valuable adjunct to the treatment of type A aortic dissection, even if midterm follow-up studies will define the clinical outcome of patients subjected to combined solutions for complex aortic disease.

\section{References}

1. Bachet JE, Termignon J, Dreyfus G, Goudot B, Martinelli L, Piquois A, et al. Aortic dissection: prevalence, cause, and results of late reoperations. J Thorac Cardiovasc Surg. 1994;108:199-206.

2. Kazui T, Yamashita K, Washiyama N, Terada H, Bashar AHM, Suzuki T, et al. Impact of an aggressive surgical approach on surgical outcome in type A aortic dissection. Ann Thorac Surg. 2002;74(suppl):S1844-7.

3. Urbanski PP, Siebel A, Zacher M, Hacker RW. Is extended aortic replacement in acute type A dissection justifiable? Ann Thorac Surg. 2003;75:525-9.

4. Roux D, Brouchet L, Concina P, Elghobary T, Glock Y, Fournial G. Type-A acute aortic dissection: combined operation plus stent management. Ann Thorac Surg. 2002;73:1616-8.

\section{Repair of a sinus of Valsalva aneurysm that had ruptured into the pulmonary artery}

Heyman Luckraz, FRCS, ${ }^{a}$ Madhav Naik, FRCS, ${ }^{a}$ Geraint Jenkins, MRCP, and Aprim Youhana, FRCS, ${ }^{a}$ Swansea, United Kingdom

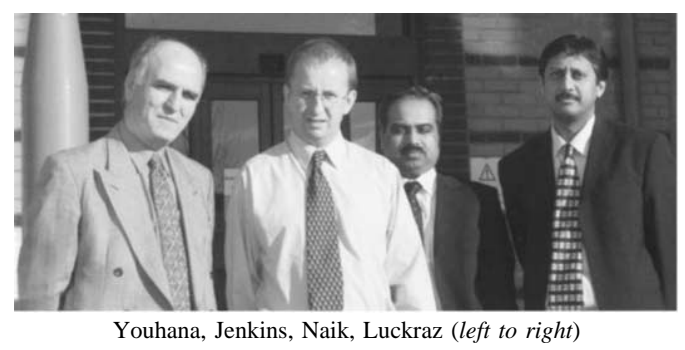

Youhana, Jenkins, Naik, Luckraz (left to right)
$\mathrm{T}$ hus far, less than 500 cases of aneurysmal rupture of the sinus of Valsalva have been reported in the literature, ${ }^{1}$ despite being first reported by Hope in 1839 . The reported prevalence is between $0.14 \%$ and $0.96 \% .{ }^{1}$ Most commonly, the clinical presentation follows the rupture of the aneurysm, although patients without rupture can present with symptoms of a space-occupying lesion causing angina, mitral incompetence, aortic incompetence, and right ventricular outflow tract obstruction.

Surgical repairs were first described independently by Morrow and colleagues ${ }^{2}$ in 1958 and Bigelow and Barnes ${ }^{3}$ in 1959. Two years earlier, Edwards and Burchell ${ }^{4}$ had published a detailed anatomicopathologic review of aneurysms of the aortic sinus. They

\footnotetext{
From the Cardiothoracic Unit ${ }^{a}$ and the Cardiology Department, ${ }^{\mathrm{b}}$ Regional Cardiac Centre, Morriston Hospital, Swansea, United Kingdom.

Received for publication Nov 18, 2003; accepted for publication Nov 24, 2003.

Address for reprints: Heyman Luckraz, FRCS, Cardiothoracic Unit, Morriston Hospital, Swansea SA6 6NL, United Kingdom (E-mail: HeymanLuckraz@aol.com).

J Thorac Cardiovasc Surg 2004;127:1823-5

$0022-5223 / \$ 30.00$

Copyright $\odot 2004$ by The American Association for Thoracic Surgery doi:10.1016/j.jtcvs.2003.11.074
}

described the lesion as being a separation between the aortic media and the heart. This might be due to either a congenital deficiency in the development of the media of the distal bulbar septum or an acquired medial degeneration caused by atherosclerosis, syphilis, and infection.

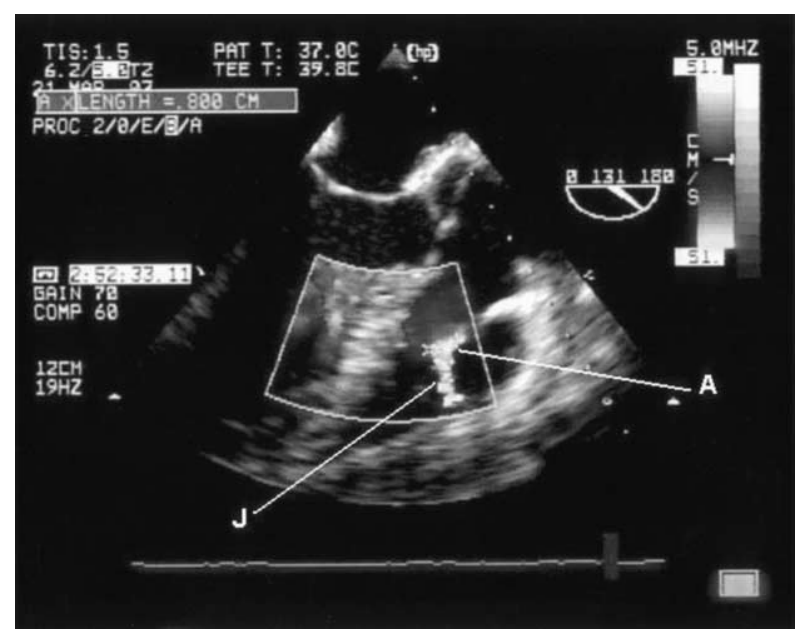

Figure 1. Transthoracic echocardiography showing the level of the aneurysmal rupture $(A)$ with an abnormal jet $(J)$ of blood from the aortic root to the main pulmonary artery. 


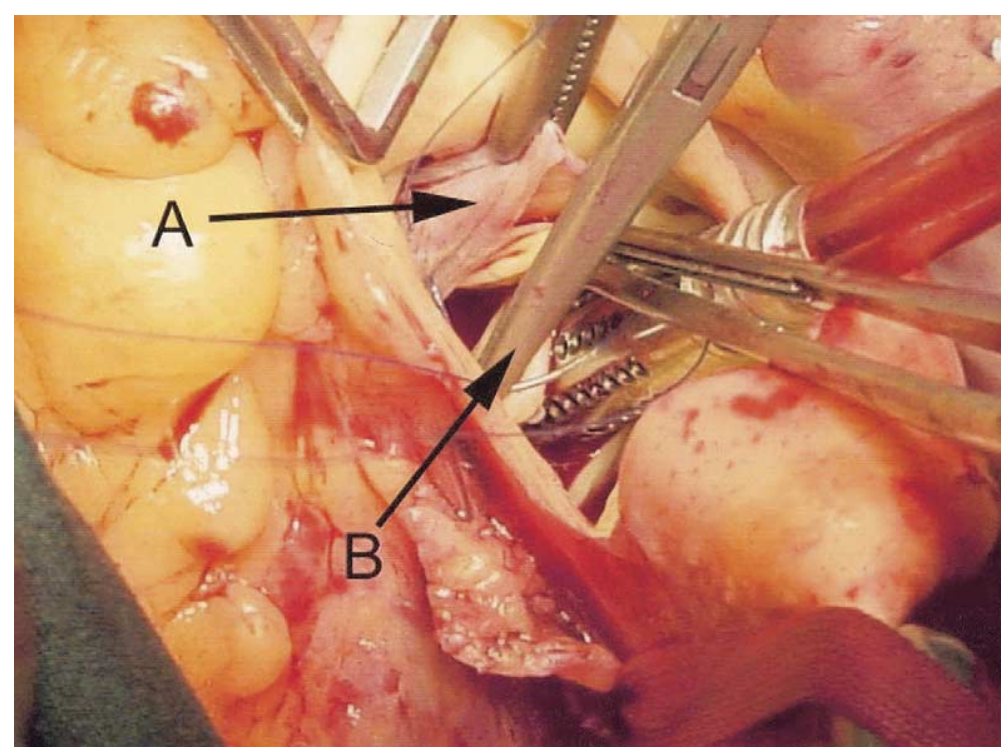

Figure 2. View through the aortotomy showing the neck of the sinus of Valsalva aneurysm $(A)$ with the surgical instrument through the ruptured wall $(B)$ into the pulmonary artery.

A review of 129 patients by Takach and coworkers ${ }^{1}$ revealed that the most common site of rupture is into the right ventricle. Although rupture in the other cardiac chambers and intrapericardial rupture have been described in the literature, rupture into the main pulmonary artery is very rare.

We describe our experience with such a case.

\section{Clinical Summary}

A 79-year-old man was admitted with an episode of sudden onset of severe chest pain radiating to his upper back and shortness of breath. Clinically, he was hemodynamically stable but had a precordial machinery murmur with evidence of moderate pulmonary edema. Transthoracic echocardiography confirmed an aneurysm and rupture of the sinus of Valsalva which is associated with the right coronary cusp (Figure 1). Right-heart catheterization revealed a step up in oxygen saturation from $60 \%$ in the right ventricle to $82 \%$ in the main pulmonary artery, with an aortic oxygen saturation of $98 \%$. The measured pulmonary pressure was $43 / 13 \mathrm{~mm} \mathrm{Hg}$, with the systemic pressure being $116 / 52 \mathrm{~mm} \mathrm{Hg}$.

The patient underwent surgical repair of the ruptured sinus. Operative findings included a dilated right ventricle, a palpable thrill over the main pulmonary trunk, and aneurysmal dilatation of the sinus of Valsalva associated with the right coronary cusp, which had ruptured into the main pulmonary artery (Figure 2). The aortic valve appeared structurally normal, and no other abnormalities were detected.

The neck of the aneurysm was plicated with a 5-0 Prolene stitch (Ethilon, Johnson and Johnson International). The wall of the sinus of Valsalva was reinforced with a double velour fabric patch (Bard Debakey, IMPRA, Inc) secured with 5-0 Prolene continuous stitches. Cardiac activity resumed spontaneously (sinus rhythm) after the release of the aortic crossclamp, and the cardiopulmonary bypass circuit was discontinued with the inotropic support of dopamine.
The patient had acute renal failure requiring renal replacement therapy from the second to the fifth postoperative days. Thereafter, he had an uneventful recovery and was discharged home 10 days after his emergency surgical procedure.

An echocardiogram before discharge confirmed successful repair of the rupture.

\section{Discussion}

Rupture of the right aortic sinus into the pulmonary artery, as in the presented case, is an uncommon finding. This most likely represent an anatomic variation of the structures associated with the right aortic sinus. In their detailed report concerning the anatomic relationship of various aortic sinuses, Edwards and Burchell ${ }^{4}$ described the right aortic sinus as being entirely related to the right ventricular outflow tract. For descriptive purposes, the right aortic sinus is divided in thirds, with the central third lying against the crista supraventricularis. The left (anterior) third of the sinus abuts the right ventricular outflow tract close to the pulmonary valve, whereas the posterior third lies against the right ventricle posteroinferior to the crista supraventricularis. The sinus associated with the right coronary cusp is more commonly affected and is also more likely to rupture, whereas the opposite is true for sinus of the left coronary cusp. The sites of communication, in decreasing order, are the right ventricle, right atrium, left atrium, left ventricle, and pericardium.

The natural history of the aneurysmal dilatation of the sinus of Valsalva is not completely understood. Patients with untreated ruptures have been reported to survive an average of nearly 4 years. ${ }^{5}$ Surgical treatment is usually associated with low mortality and excellent long-term outcome. ${ }^{1}$ Surgical intervention is recommended in both ruptured and nonruptured cases, especially if there are symptoms of a space-occupying lesion. Management strategies involve plication, patch repair, aortic valve surgery, and aortic root replacement with reimplantation of the coronary arteries. 


\section{References}

1. Takach TJ, Reul GJ, Duncan JM, Cooley DA, Livesay JJ, Ott DA, et al. Sinus of Valsalva aneurysm or fistula: management and outcome. Ann Thorac Surg. 1999;68:1573-7.

2. Morrow AG, Baker RR, Hanson HE. Successful surgical repair of a ruptured aneurysm of the sinus of Valsalva. Circulation. 1958;24: 533-8.
3. Bigelow WG, Barnes WT. Ruptured aneurysm of aortic sinus. Ann Surg. 1959;150:117-21.

4. Edwards JE, Burchell HB. The pathological anatomy of deficiencies between the aortic root and the heart, including aortic sinus aneurysms. Thorax. 1957;12:125-39.

5. Sawyers JL, Adams JE, Scott SW Jr. Surgical treatment for aneurysms of the aortic sinuses with aorticoatrial fistula: experimental and clinical study. Surgery. 1975;41:46-8.

\title{
Anatomic variations of the radial artery: Significance when harvesting for coronary artery bypass grafting
}

\author{
Abdallah K. Alameddine, MD, ${ }^{a}$ Viktor K. Alimov, MD, ${ }^{\mathrm{b}}$ Richard M. Engelman, MD, John A. Rousou, MD, \\ Joseph E. Flack III, MD, ${ }^{\mathrm{b}}$ David W. Deaton, MD, ${ }^{\mathrm{b}}$ and Daniel T. Engelman, MD, ${ }^{\mathrm{b}}$ Salem and Springfield, Mass
}

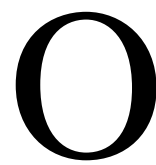
ver the past decade, the radial artery (RA) has gained wide acceptance as a useful vascular conduit for coronary artery bypass grafting with a very good midterm patency rate.

In addition to preoperative assessments of the ulnar artery collateral blood supply, it is crucial to understand the anatomic details of the RA harvesting site to avoid neurovascular complications of the forearm. Because anatomic variations of the RA in the arm are common in human subjects, ${ }^{1,2}$ it is more likely that these complications are even higher in frequency. ${ }^{3}$ We have encountered a left arm duplication of the RA where this vessel runs above the deep fascia in the proximal and mid forearm, and its course is somewhat more medial than when the RA is located beneath the deep fascia. This vessel is called the superficial RA. We discuss the anatomic findings, and on the basis of our observation in this case, we recommend that the incision should be slightly modified and should be placed more medially along the medial border of the flexor carpi radialis muscle.

\section{Anatomic Findings}

The anatomic variation was discovered intraoperatively when an accessory RA branch (or duplication) was found. We designated this anatomic variation as the RA accessory because of its significant size. The superficial branch RA (Figure 1), the larger of the

\footnotetext{
From the Department of Cardiothoracic Surgery, ${ }^{a}$ North Shore Medical Center, Salem, Mass, and the Division of Cardiac Surgery, ${ }^{\mathrm{b}}$ Department of Surgery, Baystate Medical Center, Springfield, Mass.

Received for publication Oct 29, 2003; accepted for publication Nov 3, 2003.

Address for reprints: Abdallah Alameddine, MD, PO Box 1139, Melrose, MA 02176 (E-mail: susan.parent@bhs.org).

J Thorac Cardiovasc Surg 2004;127:1825-7

$0022-5223 / \$ 30.00$

Copyright $\odot 2004$ by The American Association for Thoracic Surgery

doi:10.1016/j.jtcvs.2003.11.075
}

two, has made itself quickly apparent just below the cubital fossa and has descended in the upper and mid forearm accompanied by a significantly large lateral brachiocutaneous nerve. Both the vessel and the nerve were located beneath the superficial fascia and were found in the subcutaneous tissue instead of being concealed by the brachioradialis muscle, as is normally the case. The true deep branch RA (Figure 2) and the superficial branch of the radial nerve remained lying anterior to the teres major muscle in the upper forearm and then anterior to the flexor digitorum superficialis and the flexor pollicis longus muscles in the lower forearm, respectively. Notably, the superficial and deep RAs, as well as the lateral brachiocutaneous nerve, have remained in a more superficial plane than the flexor carpi radialis muscle and were somewhat in a more medial position. Had a more lateral incision been made, these 3 structures would have been in harm's way, being located directly under the skin and in a more medial and superficial positions beyond the medial portion of the brachioradialis muscle.

\section{Surgical Technique}

Having taken heed of this anatomic variation of the RA, we describe herein and have recently adopted a slightly modified technique of harvesting. It consists of making a more medial curvilinear incision bordered by the midportion of the flexor carpi radialis muscle belly in the upper two thirds of the forearm. The incision is continued all the way down to the white, shiny nacre and flat tendon of that muscle located in the lower third of the forearm. This incision is a slight modification of the one described by others, ${ }^{4}$ in which the incision stopped at the lateral border of the brachioradialis muscle. With the intent of protecting the neurovascular structures, the dissection begins and proceeds from the medial to lateral regions of the forearm once the entire course of the flexor carpi radialis muscle is visualized under the incision. The remainder of the dissection continues as traditionally practiced.

All wounds have healed with no hand ischemia, and no skin flap necrosis was observed. Of the 520 RAs harvested with this technique by one surgeon (AKA), only one patient experienced temporary distal forearm dysesthesia, and he fully recovered his sensation within 6 weeks. 